\title{
ASO Visual Abstract: Surgical Outcomes for Cancer Patients Undergoing Elective Surgery after Recovering from Mild to Moderate SARS-CoV-2 Infection
}

Anai N. Kothari, $\mathrm{MD}^{1}$, Sandra R. DiBrito, $\mathrm{MD}^{1}$, J. Jack Lee, $\mathrm{PhD}^{2}$, Abigail S. Caudle, $\mathrm{MD}^{3}$, Mark W. Clemens, $\mathrm{MD}^{4}$, Vijaya N. Gottumukkala, $\mathrm{MD}^{5}$, Matthew H. G. Katz, MD ${ }^{1}$, Anaeze C. Offodile, $\mathrm{MD}^{4}$, Abhineet Uppal, MD $^{6}$ on behalf of D3CODE Team, and George J. Chang, MD, MS ${ }^{6}$ (1)

${ }^{1}$ Department of Surgical Oncology, University of Texas MD Anderson Cancer Center, Houston, TX; ${ }^{2}$ Department of Biostatistics, University of Texas MD Anderson Cancer Center, Houston, TX; ${ }^{3}$ Department of Breast Surgical Oncology, University of Texas MD Anderson Cancer Center, Houston, TX; ${ }^{4}$ Department of Plastic Surgery, University of Texas MD Anderson Cancer Center, Houston, TX; ${ }^{5}$ Department of Anesthesia and Perioperative Medicine, University of Texas MD Anderson Cancer Center, Houston, TX; ${ }^{6}$ Department of Colon and Rectal Surgery, University of Texas MD Anderson Cancer Center, Houston, TX

A wait time of 20 days after recovery from mild to moderate SARS-CoV-2 infection appears to be safe for cancer patients undergoing low-risk elective surgery.
Patients requiring inpatient treatment of COVID-19 before surgery are at increased risk for adverse events (https://doi. org/10.1245/s10434-021-10291-9).

\section{Surgical Outcomes in Cancer Patients Undergoing Elective Surgery} After Recovering from Mild to Moderate SARS-CoV-2 Infection

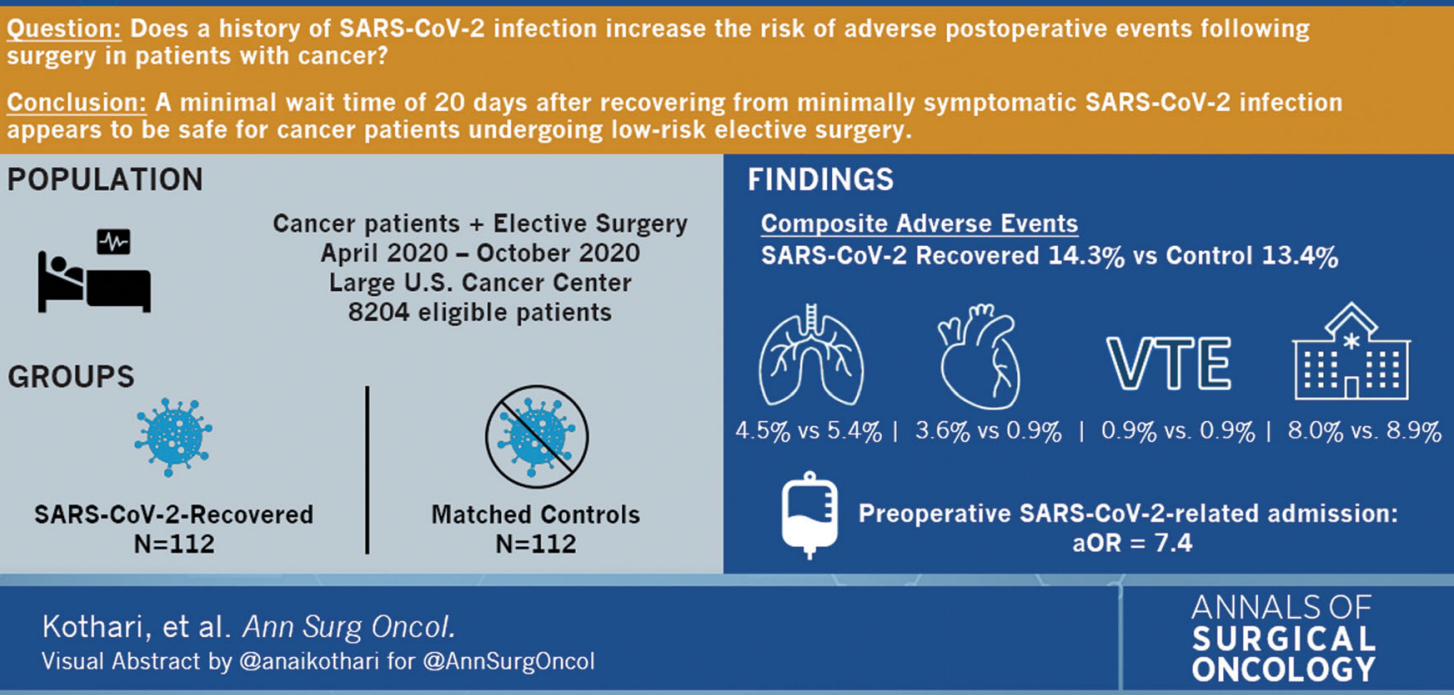

(C) Society of Surgical Oncology 2021

Published Online: 10 August 2021

G. J. Chang, MD, MS

Publisher's Note Springer Nature remains neutral with regard to jurisdictional claims in published maps and institutional affiliations.

e-mail: gchang@mdanderson.org 